\title{
On Hong Kong's Feelings and Educational Implication in Lin Xi's Lyrics Meng $\mathrm{He}$
}

\author{
College of Humanities and Social Sciences, China Jiliang University,Hangzhou 310000,China \\ 1134253962@qq.com
}

Keywords: Lin Xi; Hong Kong; the other

\begin{abstract}
As a native Hong Kong man born in Hong Kong and growing up in Hong Kong, Hong Kong is the city of Lin Xi's heart and his "home". He integrated his attention and shaping of this "home" into the lyrics. Lin Xi observed the emotions and spirit of the people in Hong Kong from the details of the little things, lacked and adhered to, observed Hong Kong's present and past, character and culture, Consider the hidden relationship between Hong Kong and the Mainland, and the West. Therefore, his lyrics are not only the carrier of Hong Kong culture, but also become a mirror. Let us truly see the beating of Hong Kong culture and the collective mood of Hong Kong people.

As a Hong Kong native who was born in Hong Kong and grew up in Hong Kong and accepted the most orthodox Hong Kong-style education, Lin Xi always has the most authentic and gentle feeling of belonging to Hong Kong, just as he did in the book "I Love Hong Kong". Writing "I haven't even thought of immigrating for a second every time since I was a child. I have loved watching the map of Hong Kong since childhood and used the matchbox as a building to build Prince Edward Road, Nathan, and Waterloo Road. I walked each way. The names of the street and street have sentiments. It is impossible for me to immigrate and can no longer visit the CD shop in Causeway Bay." I can see that Lin Xi loves her. Hong Kong, but this love is not blind but based on understanding. He is familiar with the streets of Hong Kong and understands the culture of Hong Kong. After witnessing the rise and fall of a series of Hong Kong's glories, he still candidly love the city. This kind of love is ultimately a sense of belonging. Hong Kong is the city of Lin Xi's heart and is his "home".

Lin $\mathrm{Xi}$ is a well-known Chinese literary word writer and has a reputation as a "word sage." He graduated from the Department of Chinese Studies at the University of Hong Kong. As an intellectual who has received higher education, his lyrics also express to some extent the Hong Kong intellectual's status quo in Hong Kong. The thinking has become a unique symbol of Hong Kong's culture.
\end{abstract}

\section{Hong Kong as the other}

In 1842, the Qing Dynasty failed in the Opium War, China signed the first unequal treaty in history, cutting Hong Kong Island to Britain. Until the return of Hong Kong in 1997, Hong Kong was still under British rule for a period of one and a half centuries. Before 1840, Hong Kong was actually a small fishing village. It seems that the development and prosperity of Hong Kong cannot be separated from the United Kingdom. For Hong Kong, which is in a primitive peasant state, Western industrial civilization has brought about a completely different economic model and social system. Under the western economic model, Hong Kong has become an open and compatible city, and the rapid economic development has gradually become a symbol of capital from a global perspective. What we are talking about is the character of Hong Kong, which is often the face of Hong Kong after its development. This recognition has not only come from Western society, but has also been promoted by Western society. It can even be said that Hong Kong is an oriental fairy tale created by Western industrial civilization. Hong Kong, as a colony, has never found its own cultural roots in Western civilization. However, long-term separation from the parent continent, economic disparities between the mainland and Hong Kong, and cultural differences have made Hong Kong unwilling to recognize the subjectivity of the mainland. Zhang Ailing once said in her novel: "Hong Kong society imitates English habits everywhere, but always likes to add to it, it seems to lose 
everything."2 Obviously, Hong Kong tried Through various forms of customary imitation to seek the recognition of Western mainstream cultures, the colonial role plays have always made Hong Kong "others", marginalized, mournful of the main consciousness, and lost the right to speak in dialogue with Western culture. The interaction with the West is not a two-way interaction, but has always been in a single mode of input, and a strong desire to be accepted by Western society. Zhang Ailing narrates what she sees in Hong Kong from the perspective of a Shanghai or mainlander. In such narrative discourse, Hong Kong is not regarded as an important part of a connection with the mainland, nor as an independent individual to pursue cultural identity. But as a follower and imitator of British culture, Hong Kong is also in a position of "otherness" in the narrative discourse of the mainland. Hong Kong has always been on the verge of approval.

From the perspective of dual narratives, the dilemma of identity that Hong Kong faces is not improved with his return. Just as Lin Xi's lyrics "the relationship is no longer the same, how can one care about it and break off." The break-up between lovers Entanglement implies that Hong Kong, which had been freed from British colonialism, is still deeply influenced by British culture.

\section{The Feeling of Hong Kong at the End of the Century}

As a modern metropolis in Hong Kong, the advantages and disadvantages of modern civilization are fully displayed here. On the one hand, Hong Kong people living in a highly developed city, and on the other hand, the high-intensity and fast-paced life has forced Hong Kong people numb to go to work in order to in order to live. Lin Xi said in a short essay entitled "Live to work or work to live." "This is Hong Kong. It is a sin to not be advancing." ${ }^{3}$ No It is difficult to see that the atmosphere of Hong Kong society as a whole forces people to devote themselves to the work of .machinery This has caused Hong Kong society to lose its imagination and vitality and its humanity. "Based on history, language, polity, geography, ethnicity, and cultural accumulation, the cultural characteristics of Hong Kong have been summed up as the character of Hong Kong." The Hong Kong people's feelings of the Sui and Tang Dynasties are the most favorable evidence that the painless rootless generation of Hong Kong was struggling on the road to identity.

The lyrics are both a mirror image of Hong Kong's popular culture and a carrier of popular culture. The lyrics of $\mathrm{Lin} \mathrm{Xi}$, which has been flourishing for more than 20 years, is a unique symbol of Hong Kong's popular culture.

Lin Xi had created three songs for the "Miracle of Dreams" album by McGovern - "Life and Death", "Inverted Dreams," and "Three Millions of Weak Water." In this series, Lin Xi changed the style of past story-telling lives. The creation of lyrics is based on his thinking about the ultimate problem in life, and on the purpose of life marching. There are such lyrics in "Inverted Dreams". "The sun rises and the sun sets. With dreams looting and grabbing. Finally, the treasure box is uncovered and found to be different from what it was supposed to be. At first, it was full of joy. Some of the toys are beautiful and wet, in order to capture the beauty of the water." A picture Hong Kong people who drew on the intoxication of desires. The gentle and direct expression of the struggle and despair of Hong Kong people in their identity and mental dilemma.

Lin $\mathrm{Xi}$ once said in an interview that "Now I hope to write the theme of $\mathrm{Du} F u$ under the assumption of Wang Wei's style of participating in social affairs." He does not love the external form of the scholar, but he has the heart which caring about the country and the world. He observes the social phenomenon of Hong Kong streets and corners, the joys and sorrows of the people in Hong Kong,and then puts into lyrics, and use lyrics to record the hardships and efforts of Hong Kong in building his own cultural identity. "I AM WHAT I AM. I always love this kind of me. The joy is that there is more than one way to happiness. The honour is that everyone is the glory of the Creator. Do not dodge and live for my chase. Ink is standing in the bright corner.I'm me, it's a fireworks of different colors. The sky is vast, I want to be the strongest bubble.I like it and let rose produce a result.In a lonely desert Put naked." This first Leslie Cheung classic masterpiece, the lyrics from Lin Xizhi's hand, the lyrics are written in the first person, the Hong Kong people's struggle in identity difficulties and tragic portrayal of the most vivid.In this song entitled "I," we can see that Lin Xi's lyrics are neither the imagination of the "Central China mentality" nor the concept 
of a British colonial country, but the emotional writing and construction imaging of Hong Kong intellectuals. His preciousness is that he dares to break the identity of the jealousy, tries to establish an independent discourse system, and pursues Hong Kong's unique cultural personality and citizen spirit. Lin Xi's lyrics became a symbol of Hong Kong's sexuality. The desperate sadness is not only the personal feelings of Lin $\mathrm{Xi}$, but also the emotional portrayal of Hong Kong people. It is the expression of Hong Kong's collective mood. Hong Kong finally became a fairy tale that let Hong Kong people down.

Assigned to the vicissitudes of the sentence, Lin Xi uses a trifling matter to record the changes of the city. Through Lin Xi's lyrics to interpret Hong Kong's cultural traits and Hong Kong people's mental attitude, we can see Hong Kong more and more clearlyin the face of identity difficulties. And helplessness, despair and hard work. As his name suggests, he walks in the streets of Hong Kong and records the joys and sorrows of Hong Kong. He has left his somniloquy in the world.

\section{References}

[1] Lin Xi. I love Hong Kong [M]. Guangxi Normal University Press. 2009

[2] Ailing Zhang. The first incense burner [M]. Flower City Press.

[3] Ying Fu. The Hong Kong Character of Lin Xi's Lyrics[J].Literature Research,2007(7)

[4] Yu D, Peng L. When does Inferring Reputation Probability Countervail Temptation in Cooperative Behaviors for the Prisoners' Dilemma Game? [J]. Chaos, Solitons \& Fractals, 2015, 78: 238-244.

[5] N. Prieto, ó. López-Campos, J.L. Aalhus, M.E.R. Dugan, M. Juárez and B. Uttaro: Meat Science, Vol. 98 (2014) No.2, p.279.

[6] M. Pla, P. Hernández, B. Ari?o, J.A. Ramírez and Isabel Díaz: Food Chemistry, Vol. 100 (2007) No.1, p.165.

[7] R.R. Pullanagari, I.J. Yule and M. Agnew: Meat Science, Vol. 100 (2015), p.156.

[8] Saudland, A., Wagner, J., Nielsen, J. P., Munck, L., N?rgaard, L. and Engelsen, S. B: Applied Spectroscopy, Vol. 54 (2000) No.3, p.413.

[9] Balabin, R. M. and Smirnov, S. V: Analytica Chimica Acta, Vol. 692 (2011) No.1-2, p.63.

[10] Leardi, R. and N?rgaard, L: Journal of Chemometrics, Vol. 18 (2004) No.11, p.486.

Lin Xi. I loved Hong Kong. Guangxi Normal University Press. 2009.]

${ }^{2}$ Ailing Zhang. The first incense. Flower City Press. 1997.018

${ }^{3}$ Lin Xi. I love Hong Kong. Guangxi Normal University Press. 2009.005

${ }^{4}$ Ying Fu. The Hong Kong Character of Lin Xi's Lyrics. Literature and Art Research. 2007(7) 